\title{
Técnica y ontología: la perspectiva heideggeriana ${ }^{1}$
}

\author{
Greta Rivara Kamaji
}

$\mathrm{L}$

a reflexión heideggeriana sobre la técnica no sólo constituye una de las más significativas en su línea, la ontología, sino que en muchos sentidos ha marcado una veta de reflexión que se ha insertado dentro de la llamada "filosofía de la tecnología", y además, podríamos afirmar que sus reflexiones al respecto continúan hoy siendo un paradigma vigente y un punto de partida pertinente para pensar filosóficamente la técnica, fundamentalmente desde la ontología.

Varios son los textos heideggerianos en los que se explicita de manera significativa el tema de la técnica, ${ }^{2}$ entre ellos nos centraremos sólo en dos que consideramos paradigmáticos: "La época de la imagen del mundo" y "La pregunta por la técnica". 3

"La época de la imagen del mundo", originalmente una conferencia que Heidegger dictó en 1938, constituye uno de los más sugerentes cuestionamientos sobre la modernidad que ha dado la filosofía en las últimas décadas.

${ }^{1}$ Desde luego no abarcaremos en este ensayo la totalidad del tema. Pretendemos únicamente subrayar algunos elementos que consideramos centrales para la discusión del tema, pero de ninguna manera se trata de un análisis exhaustivo, ya que desbordaría los límites y las intenciones que nos hemos propuesto para este ensayo.

${ }^{2}$ Nos referimos fundamentalmente a las conferencias que Heidegger dictó como parte del ciclo "Einblick in das, was ist" que se llevó a cabo en Bremen en 1949, estas son: Die Kehre, Die Gefahr, Das Gestell y Das Ding. Das Gestell fue pronunciada por Heidegger nuevamente en 1953 bajo el título Die Frage nach der Technik. Entre otros textos al respecto del tema podemos mencionar Bauen Wohnen Denken que junto con Das Ding y Die Frage nach der Technik se encuentran en el volumen Martin Heidegger, Vorträge und Aufsätze, Pfullingen, 1954.

${ }^{3}$ M. Heidegger, "La época de la imagen del mundo", en Caminos de bosque. Trad. de Helena Cortés y Arturo Leyte. Madrid, Alianza, 1997, y M. Heidegger, "La pregunta por la técnica”, en Conferencias y artículos. Trad. de Eustaquio Barjau. Barcelona, Ediciones del Serbal, 1994. (Col. Odós) 
¿Cuál es la modernidad que a Heidegger le interesa o qué fenómenos de la modernidad son los que le preocupan de una manera fundamental? ¿Qué lee en la modernidad de manera que de su lectura brota el tema de la técnica como problema y la preocupación por su despliegue y su devenir? ¿Cómo inserta Heidegger sus preocupaciones ontológicas -clave y línea de todo su pensamiento- en una reflexión sobre la modernidad y la técnica moderna que según él alcanzan nuestros días?

Recordemos que la modernidad le interesa fundamentalmente por lo que Heidegger denomina historia del ser, como experiencia del ser, como modo de relación con el mundo que devela, en última instancia, una de las expresiones más significativas de la metafísica como historia del olvido del ser en favor del ente.

Por ello, en el texto heideggeriano impera, en primera instancia, una consideración sobre la modernidad filosófica desde Descartes y Kant, hasta Hegel y Nietzsche, no sin pasar por un constante diálogo con toda la tradición por él llamada metafísica, diálogo que atraviesa toda su obra.

En el texto mencionado, Heidegger comienza preguntándose por la manera en la que se despliega el ser del hombre y de su mundo dentro de lo que él llama "la época de la imagen del mundo", es decir, la modernidad; expresión que asigna, según nuestro autor, una de las maneras en que la metafísica misma se ha mostrado y ha configurado al mundo.

Es desde esta perspectiva que Heidegger se pregunta ¿qué es eso, la modernidad? Desde luego, no le interesa primariamente como un momento en la historia de occidente o como un fenómeno social, sino fundamentalmente como historia del ser, ya que la reflexión surge desde su interés ontológico.

Una de las ideas fundamentales que según Heidegger rige toda la modernidad es la idea del progreso técnico y científico que recae justo en una muy fehaciente confianza en el futuro, basada a su vez en una concepción exclusivamente lineal del tiempo y de la historia.

Una confianza y una fe básicas estaban detrás de todo esto: el humanismo que sostenía los engranajes de la modernidad y su apuesta básica en el porvenir y en las posibilidades emancipatorias del hombre, así como su domino de la naturaleza; asentado todo ello en un profundo culto a la razón. ¿De qué tipo de racionalidad está hablando Heidegger? ¿Cuál es la especificidad que ve en la racionalidad moderna y que constituye la mayor fe de la época y sobre la cual se asientan las concepciones del hombre y del mundo?

Una racionalidad que descansa y se asegura a sí misma en los exitosos eventos de las ciencias físico-matemáticas, que de acuerdo con Heidegger, promueven como nunca antes un creciente afán de dominio que llegaría a su paroxismo máximo con el puesto central que se da el hombre en la modernidad; éste se coloca como amo y señor del universo, lugar que se otorga a 
partir de la consolidación de su ser entendido como exclusivamente racional. La categoría moderna de sujeto traduce para Heidegger esta experiencia. ${ }^{4}$

El hombre se convierte en sujeto teórico, es decir, en aquel ente que se encuentra en el mundo para conocerlo, para dominarlo, para controlarlo, él es la sede única de toda certeza y toda evidencia; a su voluntad y a su racionalidad se reduce la totalidad de la existencia; amo y señor, déspota del ente a partir del cual todo se explica y todo se entiende. El mundo no es más un mundo sino que es el objeto al cual se enfrenta el sujeto; el mundo como objeto es ahora lo representado a la racionalidad del sujeto. Es por eso que el mundo se convierte en imagen, como afirma Heidegger en el título mismo de su texto.

La dimensión global de la llamada "tecnociencia" implica para Heidegger de manera inédita y por ello inaugural en la modernidad una alianza, una conjunción entre ciencia y técnica; ahora unidas precisamente por las ciencias físico-matemáticas.

La especificidad se debe ahora al hecho de que el conocimiento del mundo se convertía, según Heidegger, en investigación y la particularidad de esto radicaría precisamente en que se podía ya trabajar sobre fenómenos previamente no sólo controlados sino producidos y generados experimentalmente.

Una idea es lo que para Heidegger no sólo está fundando este estado de cosas sino produciéndolo simultáneamente; la creencia en que toda investigación, todo conocimiento, debe estar destinado a producir resultados de manera no sólo concreta y palpable sino de manera inmediata y ello porque la razón que opera detrás es precisamente una razón operatoria, eficaz, aquella que calcula, que mide, que puede controlar al mundo, el cual ha convertido en una totalidad sistemática reductible al cálculo y a la mensura.

Es en este sentido que Heidegger afirma que la singularidad y novedad de la manera en que se investiga y se increpa al mundo a ser investigado, no radica necesariamente en la creación y generación de métodos precisos y adecuados, sino fundamentalmente en el hecho de que previamente se calcula, se acota aquello que se necesita investigar; esquema en el cual el mismo método o la misma manera de proceder está ya predeterminada. Es decir, se prefigura

\footnotetext{
${ }^{4}$ Recordemos que en la modernidad la idea del sujeto designa fundamentalmente el "yo" del hombre. Para Heidegger, la palabra latina subjectum que traducía de alguna manera la palabra griega $v \pi о \kappa \varepsilon \mu \varepsilon \varepsilon v o v$, y que en cierto sentido señalaba el carácter de fundamento que sostiene los caracteres accidentales de las propiedades del ente, transforma radicalmente su significado en la idea del sujeto de la filosofía moderna, un subjectum que se reduce a ser la sustancia no ya de un ente u otro sino fundamentalmente el "yo" del hombre. Al respecto, $c f$. M. Heidegger, "La época de la imagen del mundo", en op. cit.
} 
lo que se mira antes de verlo, de modo tal que la correspondencia de lo investigado con aquella predeterminación es lo que constituye a su vez la validez de la investigación, esto es, su programación con carácter apriorístico.

Con todo esto, se da entonces para Heidegger un cambio radical en nuestra manera de percibir la naturaleza; ésta se convierte en objeto y se torna a su vez un sistema perfectamente encuadrable y controlable, un sistema cerrado en el cual nada escapa a los presupuestos de la teoría; de ello resultan las nociones de rigor y exactitud en las cuales la investigación puede y debe ajustarse a la realidad investigada que de hecho, como decíamos, ha sido previamente pre-escrita, proscrita.

Las preguntas heideggerianas con respecto a tal fenómeno, el de la tecnociencia moderna, serían en rigor ¿qué idea del ente está en la base de tales concepciones?, ¿qué relación con el mundo implican tales concepciones?, ¿qué relación, en última instancia, se da con el ser a partir de todo ello? ¿Cómo modifica esto nuestra comprensión del mundo y de nosotros mismos? Y más aún ¿̇cuál es la esencia de esa relación?

El mundo se revela, según Heidegger, como disponibilidad. La nueva investigación se aproxima a las cosas para disponer de ellas, las representa con el fin de poder medirlas y calcularlas lo cual implica también dominación.

Que el ente se devele en la modernidad como disponibilidad quiere decir que se devela como objetividad y la certeza de la representación se llama ahora verdad. La totalidad del ente se reduce a ser objeto de la representación de un sujeto enteramente racional y debido a ello es la sede de las evidencias $\mathrm{y}$ de las verdades.

La metafísica cartesiana constituye según Heidegger la expresión de tal modelo: el de la conversión del hombre en sujeto racional y la del mundo en objeto representado a tal sujeto; operación a partir de la cual la totalidad no sólo es susceptible de ser explicada sino dominada por ese sujeto, ya que todo se reduce a las representaciones que él se haga.

Este proceso manifiesta para Heidegger el ser mismo de la modernidad y la tecnociencia moderna. Ahora bien, con ello afirma que el ser de la modernidad no es algo técnico, no es un evento de la técnica. La esencia de la técnica se relaciona con el olvido del ser en favor del ente. Vamos entonces a $\mathrm{La}$ pregunta por la técnica o más bien a la pregunta por la esencia de la técnica que, según Heidegger, lejos de estar fuera de la metafísica es en última instancia su culminación misma.

La esencia de la técnica muestra una determinada manera de develarse la realidad en la cual la totalidad del ente aparece en su máxima reducción a objeto y Heidegger agrega que ahí se incluye por supuesto el hombre. En el imperio del ente, del objeto, de la cosa cognoscible, lo que se oculta es el ser y fundamentalmente el ser del hombre. Aquí radica para Heidegger el peligro 
de la técnica y no en los objetos técnicos; esto es, que el ser del hombre se reduce a ser un objeto más de la explotación, del cálculo, un ente aprovechable, controlable y aun producido.

Si la técnica solicita de la naturaleza, del mundo, cada vez más, cada vez más recursos y conocimientos, en el caso del hombre es su ser mismo el que es solicitado por la técnica a convertirse en objeto. Se le solicita algo a cambio, que según Heidegger, es su propia humanidad, su diferencia ontológica para reducirlo a cosa y sólo a cosa.

Es a esto a lo que se refiere Heidegger cuando dice que la esencia de la técnica no es nada técnico, que su despliegue y mostración no es nada técnico y es justo ahí donde radica su peligro, su gravedad; es entonces, el alcance ontológico de tal composición del mundo lo que le preocupa a Heidegger. Es la técnica en tanto un modo de desvelarse el ser. ¿Cuál es ese modo de acaecimiento?

En la descripción heideggeriana observamos un dato significativo: el hecho de que la naturaleza es dispuesta y solicitada por la técnica, que es puesta ahí para poder disponer de ella. Este disponer tiene para Heidegger dos implicaciones importantes: que se torna por un lado en un provocar y por otro en un exigir.

Una vez que se ha convertido a la naturaleza en el objeto del que un sujeto dispone a modo de totalidad calculable, se puede además de disponer de ella, provocarla y exigirle que libere sus recursos y que lo haga además de manera incesante, insaciable, con lo cual a su vez se la tiene a entera y a completa disposición.

Ahora bien, ¿qué sucede con el ser del hombre y por qué ahí se encuentra para Heidegger el peligro? ¿Cómo se altera o se modifica el ser del hombre en tal relación?

Habíamos señalado, siguiendo a Heidegger, que el hombre en la modernidad se había dispuesto a sí mismo como sujeto, necesitaba constituirse en sujeto para representarse al mundo como objeto y racionalizarlo, pero no sólo eso sino que ese sujeto que conoce, que es el sitio de acaecimiento de toda certeza, él mismo ha de producirse como el que demanda incesantemente de la naturaleza, ya que es él el que exige, el que provoca. Se obliga a sí mismo a convertirse en el eterno solicitante de la naturaleza con el fin de disponer de ella, de provocarla. Para Heidegger la importancia de ello radica en que el hombre al provocar a la naturaleza se provoca a sí mismo, solicitando de ella, se solicita a sí mismo y altera su ser al convertirse en el ente que solicita de sí mismo el convertirse en disponente y demandante.

Lo que sucede aquí, según Heidegger, es que si el hombre había solicitado y exigido es él ahora el que es solicitado y exigido entrando a formar parte de un círculo y una relación que ya no puede controlar, él es ahora quien es 
controlado por la técnica, demandado, provocado a comportarse siempre como solicitante y en ello es ya solicitado. Él mismo no escapa a su propia demanda, a su propia solicitud, a su propia violentación; tras violentar a la naturaleza procede a violentar su ser para exigir y arrancar de él un modo de ser, exigido por un estado de cosas que él mismo ha fundado; es él quien está a disposición de lo que había generado para disponer de todo lo demás.

Si la naturaleza había adquirido el papel de "fondo fijo acumulado" como le llama Heidegger, es decir, como disponibilidad, es el hombre también quien entra a formar parte de ese fondo.

Este modo de acaecimiento del ser es llamado por Heidegger la época de lo Gestell que, en última instancia, expresa ese disponer por parte del hombre que lo dispone a él a seguir disponiendo, demandando y exigiendo.

En esta exigencia, según Heidegger, lo que se le pide al hombre, y ahí está el peligro, es su esencia misma para reducirse a cosa, es por esto que la técnica como problema ontológico no puede abordarse desde la técnica misma en su sentido instrumental y operativo, sino en la medida en que implica un modo histórico-ontológico de desocultarse el ser, es por ello, entonces, necesario preguntarse por su esencia.

En este sentido, desde la perspectiva de Heidegger no es la técnica el peligro, no es la técnica lo que amenaza el ser del hombre, sino su esencia, su acaecer como Gestell, es decir, esa relación de demanda y demandante.

En Introducción a la metafísica ${ }^{5}$ Heidegger nombra a esta manera de desvelarse el ser "el oscurecimiento del mundo y el empobrecimiento del espíritu", realizando una especie de diagnóstico que traduce aquí aquel peligro, el del estado solicitado-solicitante del hombre en términos de oscurecimiento del espíritu. ¿Qué entiende Heidegger por espíritu? A nivel de Introducción a la metafísica y por el contexto en el que Heidegger introduce tal noción, entendemos que espíritu es la instancia, la metáfora con la que Heidegger resiste a la razón instrumental, calculadora y dominadora. Espíritu es la estructura creativa, creadora del ser del hombre que le abre a posibilidades infinitamente. También por ello es diferencia ontológica.

El peligro es que esa estructura se reduzca también a objeto dispuesto, a instrumento de cálculo y medida, en otras palabras, el peligro es para Heidegger que el espíritu se convierta en instrumentalidad a disposición de la técnica. Doblemente grave resulta esto, ya que para Heidegger sería precisamente el espíritu como conciencia creadora la instancia que puede escapar a los lineamientos de la racionalidad instrumental y tecnocientífica; si algo podría

${ }^{5}$ M. Heidegger, Introducción a la metafísica. Trad. de Ángela Ackermann Pilári. Barcelona, Gedisa, 1997. 
hacernos escapar de un destino meramente tecnificado, son nuestras posibilidades creadoras y si esta estructura cae en el dominio de la racionalidad exclusivamente instrumental entonces acecha el máximo peligro: la pérdida de nuestra diferencia ontológica, es decir, de nuestra humanidad.

De hecho, coincidimos con la argumentación que al respecto da Pedro Cerezo, quien asegura que:

[...] el principio de razón suficiente se ha verificado o cumplido exhaustivamente en la construcción científico/técnica de la realidad. La onto-teo-logía, en cuanto ontotecnología, hace valer su pretensión absoluta en la misma sustancia del mundo. En él se ha realizado la razón demiúrgica universal. ${ }^{6}$

Por ello, afirmamos nuevamente que la técnica, o mejor dicho, una reflexión sobre su esencia, no puede reducirla "a un sistema de artefactos o a un régimen de operaciones que el hombre tiene en su haber, sino a una figura de mundo, o más exactamente, a un modo histórico/ontológico de desocultación". ${ }^{7}$ Es en este modo de darse el ser, en el que la vida toda queda reducida a un sistema de demanda y producción, en el cual el control de la naturaleza se convierte en el móvil de dicho sistema.

Dado este estado de reducción de la vida a aquel sistema, cabe entonces señalar que Heidegger no está proponiendo la generación de una nueva moral frente a la técnica (o las tecnologías) que regule y limite la desproporción de su violencia con respecto a la naturaleza. Es importante mencionar que aunque en ocasiones podríamos percibir cierto tono catastrofista en la reflexión heideggeriana -como comenta Pedro Cerezo con respecto a los tonos "cuasi proféticos, a la perversión demoniaca del espíritu por el principio del cálculo"8 que encuentra en Introducción a la metafísica - hemos señalado que toda la argumentación heideggeriana intenta sacar a la reflexión en torno a la técnica justamente de esos niveles de análisis que se refieren a posiciones de aceptación o rechazo frente a la técnica.

Con ello, Heidegger precisa que el acaecer de la técnica obedece a un destinar ontológico del ser y que es a partir de ahí de donde proviene el peligro, el cual consistiría en un modo de acaecimiento del ser. Por lo tanto, aquel estado de penuria en el que la técnica nos ha dispuesto no se transfor-

6 Pedro Cerezo, "Metafísica, técnica y humanismo", en Juan Navarro y Ramón Rodríguez, comps., Heidegger o el final de la filosofía. Madrid, Editorial Complutense, 1993, p. 69.

${ }^{7}$ Ibid., pp. 69-70.

${ }^{8}$ Ibid., p. 77. 
ma ni cambiando la técnica, ni cambiando necesariamente nuestra actitud frente a ella. De cualquier modo, un cambio de actitud resultaría prácticamente imposible, puesto que, como pregunta Cerezo, ¿cómo reconocer la penuria extrema del mundo científico-técnico si es precisamente en la tecnología en donde el mundo organizado técnicamente se afirma como si estuviera fuera de la penuria?

Es necesario, pues, el advenimiento y consumación del nihilismo de la metafísica para que ahí, en su culminación, el pensar pueda ver en lo más olvidado y oculto del ser, al ser que se manifiesta en la esencia de la técnica. ¿A quién pertenece pues la posibilidad de ultrapasar el peligro de la técnica? Para Heidegger ello no está en manos del hombre, mucho menos en las de aquel que ha sentido tener el universo a sus pies; la posibilidad pertenece al ser y en esa y sólo en esa medida le pertenece también al hombre en su pertenencia al ser.

Es entonces, por esta vía por la que la reflexión heideggeriana en torno a la técnica transita, por ello insistimos en que "Lo peligroso no es la técnica. No hay nada demoniaco en la técnica, lo que hay es el misterio de su esencia".

${ }^{9}$ M. Heidegger, "La pregunta por la técnica", en op. cit., p. 29. 